\title{
Enhanced flame retardancy of flax bio-composites for the construction market
}

\author{
Nayra Uranga Loredo and Javier Sacristan Bermejo* \\ Polymers and Composites Group, Acciona Technological Center, Valportillo II n8, Madrid, Spain
}

\begin{abstract}
Bio-composites made of natural fibres are an attractive alternative to conventional composites with synthetic fibres such as glass or carbon fibres not only because of their intrinsic properties but also because of their contribution to sustainability. However, natural fibres are flammable, and bio-composites need to be protected against fire for safety reasons but also to meet the strictest EU regulations for the transportation and construction sectors. Thermosetting composites need high loadings of flame retardant additives to achieve satisfactory results in terms of flammability which may lead to significant deterioration in their mechanical properties. This work explores the possibility of reducing the flammability of flax bio-polyester composites with potential use in the transportation and construction sectors through the combination of several novel fire retardant additives, which are halogen-free and considered environmentally friendly.

Cone calorimeter tests indicate that proper combinations of fire retardant additives such as alumina trihydrate, ammonium polyphosphate and Exolite 740 reduced heat release rate and flammability up to a $60 \%$; delaying the ignition time with respect to the unfilled material. These results were achieved at concentrations much lower than those with traditional solutions. However, the addition of dimethyl propyl phosphonate to the resin formulation with alumina trihydrate and ammonium polyphosphate failed to demonstrate any significant synergistic effect at reducing the heat release rate.
\end{abstract}

Keywords: Bio-fibres, bio-resins, fire retardant additives, bio-composites

\section{Nomenclature}

$\begin{array}{ll}\text { ATH } & \text { Aluminium trihydrate } \\ \text { APP } & \text { Ammonium polyphosphate } \\ \text { DMPP } & \text { Dimethyl phosphate } \\ \text { DMA } & \text { Dynamic mechanical analysis } \\ \text { TGA } & \text { thermogravimetric analysis } \\ \text { DTG } & \text { first derivative of the TGA curve } \\ \text { pHRR } & \text { Peak heat release rate } \\ \text { THR } & \text { Total heat release rate } \\ \text { TTI } & \text { Time to ignition }\end{array}$

MARHE Maximum average of heat emission

\footnotetext{
*Corresponding author: Javier Sacristan Bermejo, Polymers and Composites Group, Acciona Technological Center, Valportillo II n8, Madrid 28108, Spain. E-mail: javier.sacristan.bermejo@acciona.com.
} 


\section{Introduction}

Fibre reinforced polymer composites are made of fibres embedded in a polymer matrix that holds the fibres together and transfers the load among them. The fibres are usually glass, carbon, or aramid, although other fibres such as paper or wood have also been used. The utilization of natural fibres in composites represents a very valuable alternative contributing to reduce the consumption of synthetic fibres and thus minimizing the environmental impact of composite materials in the construction sector. Thermosetting and thermoplastic composites made of renewable products such as natural fibres have lower embodied energy than those reinforced with mineral fibres. They are also safer for operatives to handle than traditional products and, finally, they can be composted or burnt for energy recovery at end of life.

With the growing concern for fossil fuel depletion and climate change, there is a strong interest in exploring renewable biomass materials as substitutes for petroleum-based feedstock (Goutianos, 2006; Aziz, 2005). In that context, bio-resins represent an environmentally friendly alternative to traditional resins. From an industrial point of view, the cost is one of the more significant barriers to the development of renewable materials. However, during the last few years the production of some bio-resins has become viable as technologies evolve, and economies of scale come on stream, along with increasing consumer awareness on the subject of recycling and the impact that materials have on the environment. Bio-polyester resins can now be used as sustainable alternatives to traditional petro-chemical derived materials in the manufacture of composite products.

However, despite the numerous advantages that bio-composites would provide to society in everyday life, there is an obvious disadvantage related to the high flammability of bio-resins and natural fibres such as sisal, jute or flax (Matkó et al., 2005). In fact, bio-composites' fire retardant performance represents one of the biggest challenges to the widespread use of these materials in the construction market (Troitzsch J., 2004). Recent studies have shown that it is feasible to improve the fire retardant behaviour of natural fibre reinforced polymer composites through the incorporation of fire retardant additives, such as halogen, nitrogen, and phosphorous-based compounds (Hull, Witkowski, Hollingbery, 2011; Bismarck, Mishra, Lampke, 2011; Lazko et al., 2013; Kandare, Chukwunonso, Kandola, 2011). Halogenated additives prevent flame spread, but have significant disadvantages producing dense smoke and corrosive combustion by-products which can have a negative impact on the environment and fire safety. The composition of these gases depends on the polymer chemistry, additives, and fire conditions. Among these gases, hydrogen chloride, $(\mathrm{HCl})$, hydrogen fluoride (HF), hydrogen cyanide ( $\mathrm{HCN})$, and carbon monoxide (CO) which is produced by almost all samples in varying amounts may be very toxic at relatively low concentrations (UNE 45545, Railway applications - Fire protection on railway vehicles -, 2005).

Other commonly used fillers are alumina trihydrate or aluminium trihydroxide (ATH) and ammonium polyphosphate (APP). Both are considered as 'greener' FR's, but their effectiveness is somewhat limited since relatively large amounts of these fillers are needed for adequate flame retardancy, which has a detrimental effect on processing and leads to possible alterations of product mechanical properties. However, the combination of ATH with other fire retardant additives such as APP, melamine pyrophosphate, or expandable graphite due to their synergistic behaviour have shown to be a very promising route to improve flame retardancy of composites with low mechanical/structural requirements (Hapuarachchi \& Peijs, 2009; El-Sabbagh et al., 2014; Dorez et al., 2013; Ricciardi et al., 2012). Depending on the chemical composition of the polymer matrix, combinations of ATH and APP have shown some synergistic or antagonistic behaviour with respect to polymer flammability (Schartel, Braun, \& Reinemann, 2003; Levchik et al., 1995).

The aim of this work is to enhance the fire retardant performance of flax fibre composites by means of combinations of four different fire retardant additives: APP, ATH, dimethyl phosphonate 
(DMPP), and Exolit 740. These additives were chosen because halogen-free products will be key to the future of the fire-retardant additive industry which is seeking for greener and safer solutions with greater flame retardant performance and lower smoke generation.

To date, these additives have not been used together to reduce flammability of a bio-polyesterflax composite system. Fire retardant performance is evaluated through cone calorimeter studies. Special attention is paid to finding the most appropriate combination and concentration of additives which would lead to bio-composites with enhanced fire retardant performance while, at the same time, maintaining optimum processability.

\section{Experimental}

\subsection{Materials}

The unsaturated polyester resin used was a bio-polyester, Enviroguard I 93271A, provided by CCP composites with a bio-content of nearly $25 \%$. A dual catalytic system was used to cure the resin: a low active oxygen content methyl ethyl ketone peroxide (supplied by Pergan inc. under the commercial name PEROXAN ME-50 LA3 X) was selected to avoid damage on natural fibre due to the exothermic peak produced during the curing reaction with a $1 \%$ cobalt octoate $(\mathrm{CoO})$ solution (provided also by Pergan inc. under the commercial name PERGAQUICK C12X). Biotex flax $2 \times 2$ twill $400 \mathrm{gr} / \mathrm{m}^{2}$ fabric was provided by Composites Evolution UK.

In order to preserve the environmentally friendly character of these composites a series of "green" fire retardant additives was selected. The flame retardant fillers used were ammonium polyphosphate, APP-422, and an intumescent mixture of additives known by the name Exolit 740, both supplied by Clariant, ATH from Hüber and a liquid fire retardant additive, dimethyl propyl phosphonate (DMPP), supplied by Lanexess. Materials used for the preparation of various laminates are given in Table 1.

Table 1

Composition of additives added to the bio-polyester resin

\begin{tabular}{lll}
\hline & Additive & Composition \\
\hline 1 & $\mathrm{CaCO}_{3}$ & Calcium carbonate, non FR additive, average particle size $10.5 \mu \mathrm{m}$ \\
2 & APP FR- 422 & Ammonium polyphosphate (phase II), average particle size $17 \mu \mathrm{m}$ \\
3 & ATH & Aluminium trihydrate with average particle size $15 \mu \mathrm{m}$ \\
4 & Exolite 740 & Intumescent system based on ammonium polyphosphate with average particle size 8-12 $\mu \mathrm{m}$ \\
5 & DMPP & Dimethyl propyl phosphonate \\
\hline
\end{tabular}

Composite laminates were prepared by hand lay-up, see Figure 1 . Hand lay-up is the simplest open moulding method of the composite fabrication processes. Reinforcing mat or woven roving was positioned manually in the open mould, and resin was brushed over and into the flax plies. Entrapped air was removed manually with rollers to complete the laminate's structure. The laminates were prepared using 4 plies of flax twill impregnated with the polymeric resin. The fire retardant additives were previously added to the bio-polyester resin and mixed with a high speed mixer for 5-10 min. The theoretical fibre volume fraction of these laminates is in the $40-50 \%$ range. Composite laminates were obtained by compression moulding of resin impregnate flax plies in a heated press. Flax fabric impregnated with the resin was cut into $10 \mathrm{~cm} \times 50 \mathrm{~cm}$ rectangles, and staked unidirectionally into a $3 \mathrm{~mm}$ height steel mould with release 

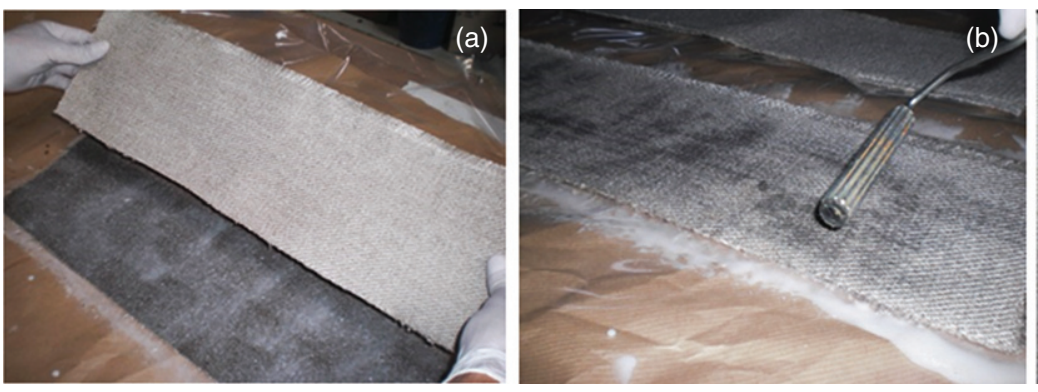

Fig. 1. Images a) and b) taken during hand lamination of $2 \times 2$ flax twill/bio-polyester resin, image c) taken after curing.

agent. The thermal curing cycle was: $60 \mathrm{~min}$ at $120^{\circ} \mathrm{C}$. The dimensions of each laminate were $10 \pm 0.5 \mathrm{~cm} \times 50 \pm 0.5 \mathrm{~cm} \times 3 \pm 0.3 \mathrm{~cm}$.

\subsection{Characterization}

The fire performance was measured with a cone calorimeter (Fire Testing Technology, UK) following (ISO 5660-1:2002. Reaction-to-fire tests, 2002). In the present study all tests were conducted in the horizontal orientation. The cone calorimeter heat flux was set at $50 \mathrm{~kW} / \mathrm{m}^{2}$, which relates to the more severe fire tests for building products (Babrauskas, 1995). Ignition was spark induced and specimens were run without a retainer frame. Specimen size was $100 \mathrm{~mm}^{2} \times 100 \mathrm{~mm}^{2}$ and 3-3.3 $\mathrm{mm}$ thick. The sample was insulated at its back surface using a $46 \mathrm{~mm}$ thick ceramic paper in order to reduce heat losses as prescribed in the ISO 5660 standard. The reported results are average values obtained from testing three specimens. The given tolerances are standard deviation of three results. The important parameters used to assess fire performance are as follows (Bakhtiyari, Taghi-Akbari, \& Ashtiani, 2015): Heat release rate (HRR), time to ignition (TTI), Total Heat Release (THR, the integral of the heat release rate), peak of heat release rate (pHRR), and the maximum average of heat emission (MARHE).

Thermal gravimetric analysis was conducted using TGA Q500 machine. Samples weighing approximately $10 \mathrm{mg}$ were subjected to pyrolysis in nitrogen and air environment to a maximum temperature of $900{ }^{\circ} \mathrm{C}$ at a heating rate of $10^{\circ} \mathrm{C} / \mathrm{min}$. The weight loss was recorded in response to increasing temperature, with final residue yield on set of degradation temperature and number of degradation steps reported.

Viscosity was measured using a Brookfield viscometer equipped with a low volume kit for measurements (Model LVF, spindle no. TR10). All tests were run triplicate (three specimens) and the results expressed as the obtained average.

\section{Results}

Polymer combustion is not a simple and easily understandable process; it occurs as a series of coupled events. The polymer is first heated to a temperature at which it starts to decompose and yields gaseous products that are usually combustible. These products then diffuse into the flame zone above the burning polymer. If there is an ignition source, they will undergo combustion in the gas phase and liberate more heat. Under steady-state burning conditions, some of the heat is transferred back to the polymer surface, producing more volatile polymer fragments to sustain the combustion cycle. Flame retardants work to stop or delay fire, but depending on their chemical composition, they interact at different stages of the fire cycle. APP and ATH can provide flame 
retardant properties by various mechanisms in either condensed or gas phase (Schartel, 2010). APP422 contains a high percentage of nitrogen and phosphorous which, in the presence of a heat source or fire, acts as a shield coating precursor because of the formation of a continuous cross linked vitreous phase called ultraphosphate (Shen, Stahlheber, \& Dyroff, 1969). On the other side, ATH starts to break down in the temperature range of $180-200^{\circ} \mathrm{C}$, releasing water in the vapour phase of combustion. The elimination of water results in an endothermic reaction, removing heat from the substrate, and thus, fewer pyrolysis products are formed. The water vapour liberated has a diluting effect in the gas phase and forms a protecting layer over the condensed phase hindering the access of oxygen to the substrate (Camino \& Luda, 1998).

However, in spite of all the advantages of using natural fibres in composites and more specifically flax fibres, when exposed to a heat source their presence causes an early ignition because the fibres' thermal degradation starts at a lower temperature $\left(\sim 210^{\circ} \mathrm{C}\right)$ than that of the bio-polyester $(>250$ $\left.{ }^{\circ} \mathrm{C}\right)$, as it can be seen from the thermogravimetric curves and first derivative of the weight loss curve (DTG curves) shown in Figure 2.
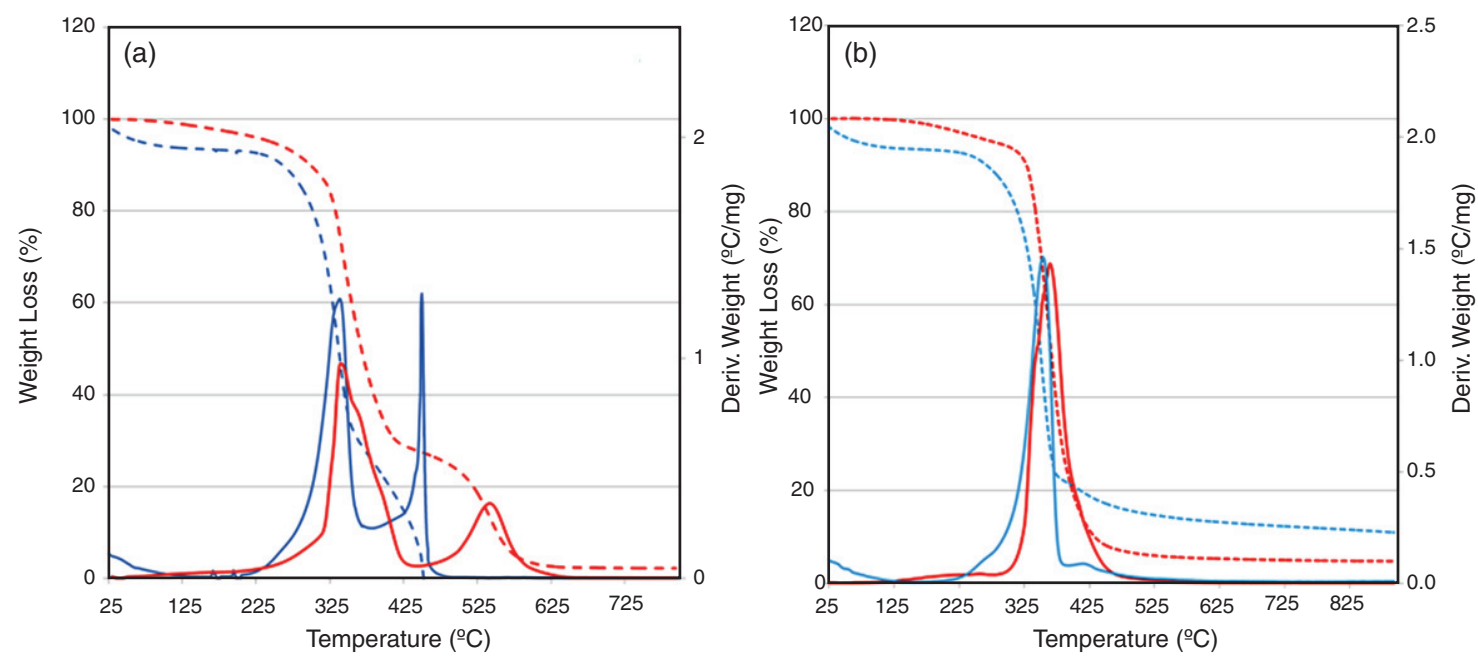

Fig. 2. TGA (dashed lines) and derivative TGA (DTG) curves (full line) of neat bio-polyester resin (red) and flax fibre (blue); a) in air and b) in nitrogen.

In air atmosphere (Fig. 2a), flax fibre shows an initial weight loss starting at $60^{\circ} \mathrm{C}$, having a maximum at $80-90^{\circ} \mathrm{C}$ associated to the loss of the moisture content; it represents about $5 \%$ in weight (Van de Velde \& Kiekens, 2002). In flax bio-composites, the total elimination of water is not possible because of the hydrophilic characteristic of the fibre. Next, it can be noted that a shoulder appears between 325 and $400^{\circ} \mathrm{C}$ that is associated to the thermal depolymerization of hemicelluloses and pectin. In an oxidative atmosphere there is partial overlapping of this peak with the exothermic peak corresponding to the decomposition of the $\alpha$-cellulose at $340^{\circ} \mathrm{C}$ (Wielage et al., 1999; Van de Velde, 2002). A third weight loss step occurs at $450^{\circ} \mathrm{C}$, which in a thermooxidative atmosphere leads to the complete degradation of the carbonaceous material. Regarding the degradation of bio-polyester, it is evident from Figure $2 \mathrm{a}$ that there are also more than one peak occurring between 225 and $625^{\circ} \mathrm{C}$ in the DTG curve, which shows that the degradation is a multi-stage process. The first process started just before $250^{\circ} \mathrm{C}$ and reached its maximum rate at $350^{\circ} \mathrm{C}$. The second weight loss process developed later and showed a higher maximum rate of decomposition at approximately $550^{\circ} \mathrm{C}$. The last stage leads to a complete degradation of the material. This behaviour is determined in the initial stages by chain scission reactions followed by 
the formation of free radicals that promote further decomposition and scission of the polyester backbone. (Ricciardi et al., 2012).

In nitrogen, (Fig. 2b), it can be noticed that the flax fibre decomposition is also a three-stage process characterized by a first step in the temperature range $30^{\circ} \mathrm{C}-90^{\circ} \mathrm{C}$ associated to the loss of moisture content, followed by a second decomposition step located in the range $225^{\circ} \mathrm{C}-400^{\circ} \mathrm{C}$ and characterized by a mass loss of $79 \mathrm{wt} \%$ and a shoulder at $420^{\circ} \mathrm{C}$ with a mass loss of $7 \mathrm{wt} \%$. The final residue of the flax fibre is $10 \mathrm{wt} \%$. In the case of the resin, the decomposition follows a two-stage process characterized by a main decomposition peak centred at $364^{\circ} \mathrm{C}$, with a mass loss of $95 \mathrm{wt} \%$. These two peaks are very close corresponding to the scission of the polystyrene bonds and to the oxidation and the breakage of the secondary bonds. The high temperature decomposition peaks observed in the TGA carried out in air are missing. In nitrogen decomposition reactions were much slower, which resulted in higher temperatures for peak 2 in comparison to air measurements. Reactions do not only happen much faster in air, but the actual reactions may also differ (e.g., the formation of hydroperoxide in air and not in nitrogen). When tested in air, flax fibre and resin are found to leave no residue at temperatures above $600^{\circ} \mathrm{C}$, indicating that all products of decomposition have been oxidized, whereas in nitrogen nearly $5-10 \%$ of carbonaceous residue remains.

So, taking into consideration these results the combination of fire retardant additives selected should decompose at lower temperatures than those of the fibre and polymer in order to maximize fire retardant protection performance of the flax fibre bio-composites compared to unprotected bio-composites.

The flammability characteristics of flax bio-polyester composites were analysed by cone calorimeter; samples were run in triplicate to minimize experimental error. The results of maximum peak heat release rate, total heat release rate, ignition time, and maximum average rate of heat emission, are summarized in Table 2.

It has been shown that the ignition time represents the flame-spread process surprisingly well (Babrauskas, 1987). The shorter the ignition time, the easier the material ignites and the flame spreads on the surface of the material with a higher velocity. Good repeatability was seen for the TTI results for the three tested specimens per formulation. Fire retardant bio-composites exhibit larger TTI than that of the unfilled laminate. A marked improvement can be seen in the ATH/APP

Table 2

The maximum rate of heat emission (MARHE), the peak heat release rate (PHRR), total heat release (THR) and ignition time of the FR bio-composites

\begin{tabular}{|c|c|c|c|c|c|c|c|}
\hline & & $\begin{array}{c}{[\mathrm{FR}]} \\
\text { Content* }\end{array}$ & $\begin{array}{c}\text { Thickness } \\
(\mathrm{mm})\end{array}$ & $\begin{array}{c}\text { MARHE } \\
\left(\mathrm{kW} / \mathrm{m}^{2}\right)\end{array}$ & $\begin{array}{c}\text { THR } \\
\left(\mathrm{MJ} / \mathrm{m}^{2}\right)\end{array}$ & $\begin{array}{c}\text { PHRR } \\
\left(\mathrm{kW} / \mathrm{m}^{2}\right)\end{array}$ & $\mathrm{Ti}(\mathrm{s})$ \\
\hline FO & - & - & 2.78 & 297 & 52.5 & 586 & 17 \\
\hline FOb & $\mathrm{CaCO}_{3}$ & 50 & 2.82 & 290 & 51.5 & 575 & 18 \\
\hline F1 & APP FR- 422 & 25 & 2,66 & 258 & 48.3 & 559 & 15 \\
\hline $\mathrm{F} 2$ & $\frac{\text { APP FR- } 422}{\text { ATH }}$ & 50 & 2,60 & 210.9 & 48.8 & 419.8 & 19 \\
\hline F3 & $\frac{\text { APP FR- } 422}{\text { ATH }}$ & 175 & 2.60 & 131,50 & 39.0 & 314,06 & 41 \\
\hline F4 & $\frac{\text { APP FR- } 422}{\frac{\text { ATH }}{\text { DMPP }}}$ & 185 & 2.70 & 203.2 & 40.7 & 452.1 & 21 \\
\hline F5 & Exolite 740 & $>75$ & 2.65 & 99,33 & 38 & 134,4 & 19 \\
\hline
\end{tabular}

*Formulation total FR content is specified in percentage relative to the total amount of resin. 
filled formulations. The FO specimen had a TTI of 17 seconds and combusted violently with large flames during testing. As the loading of APP/ATH increases, the TTI was prolonged reaching a maximum value of $41 \mathrm{~s}(\mathrm{~F} 3)$. This may be due not only to the barrier effect of the fire retardant additives, but also to the fact that there is a lower amount of natural fibres exposed at the surface.

The primary result from the cone calorimeter test is the measurement of heat energy released over a specific unit of time - that is the heat release rate. A high heat release rate translates to rapid temperature changes, faster flashover times and an increase in the production of the products of combustion. After ignition, surface temperature and the HRR rapidly rises and reaches its peak value, which depends upon the type of the material and its combustible content. The average and peak values of HRR of the burned specimens are given in Table 2. The combustion of the reference sample (FO) which does not contain FR additives is the most exothermic with $52.5 \mathrm{MJ} / \mathrm{m}^{2}$ and $586 \mathrm{~kW} / \mathrm{m}^{2}$ as THR and pHRR respectively. The addition of APP even at a low concentration, $25 \mathrm{phr}$, reduced the $\mathrm{pHRR}$ to $559 \mathrm{~kW} / \mathrm{m}^{2}$. These results can be explained by a combination of two effects: as more inorganic filler is introduced into the resin, less resin is available for combustion and to the shielding effect of the ultraphosphate layer formed during the combustion. The introduction of ATH to that formulation, with an overall fire retardant content of $50 \mathrm{phr}$ lead to a considerable reduction in its flammability with up to a $25 \%$ reduction in the THR and pHRR values. As the ATH loading increases from 25 to $125 \mathrm{phr}$ (F2 and F3) the pHRR decreases from 419.8 to $314.1 \mathrm{~kW} / \mathrm{m}^{2}$, and the THR from 48.8 to $39 \mathrm{MJ} / \mathrm{m}^{2}$ respectively. The results show that the increase of ATH concentration in combination with APP has a very positive effect in reducing both the pHRR and THR values. This was thought to be due to a combination of three effects; (i) fuel replacement effect, (ii) the ATH endothermic water cooling effect which contributes to reduce the combustion of the specimen. This was evident from the pHRR values of the samples F3 with ATH and APP and the sample FOb with $50 \mathrm{phr} \mathrm{CaCO}_{3}$, which were 419.8 and $586 \mathrm{~kW} / \mathrm{m}^{2}$ respectively and (iii) when ATH and APP reacts, produce a more thermally stable $\mathrm{P}-\mathrm{Al}-\mathrm{O}$ surface layer instead of the less thermally stable P-O layer formed in specimens loaded only with APP. Results from specimens F3 and F2 are a good example of that behaviour. As the fire retardant loading increased from $25 \mathrm{wt} \%$ to $175 \mathrm{wt} \%$, a $35 \%$ enhancement on the flame retardancy is clearly observed through the reduction on the pHRR, THR and increase TTI values. However, addition of DMPP did not produce any positive effect on the pHRR and THR. In fact, pHRR and THR increases to $452 \mathrm{~kW} / \mathrm{m}^{2}$ and $41 \mathrm{~kW} / \mathrm{m}^{2}$, with respect to the formulation F3.

Next, an intumescent FR blend of additives with synergists for unsaturated polyester resins, Exolite 740, was added to the resin formulation. The F5 system reached the lowest pHRR and THR among all the samples. pHRR and THR values, which were $134.4 \mathrm{~kW} / \mathrm{m}^{2}$ and $38 \mathrm{MJ} / \mathrm{m}^{2}$ respectively, are approximately $80 \%$ and $50 \%$ lower than the unfilled laminate. Compared to the fire retardant compositions F1, F2 F3 and F4, it also has lower pHRR and THR values which are $75 \%$ and $2 \%$ lower for $\mathrm{F} 1$ and $57 \%$ and $20 \%$ lower for F3 respectively. That intumescent fire retardant additive is a mixture of different additives that work together under fire conditions to form a protective barrier (carbon foam) that "rises up in response to heat", protecting more efficiently the underlying substrate.

The addition of fire retardant additives to the bio-polyester resin has shown that it is feasible to produce bio-composites with lower THR and pHRR and higher time to ignition than the unprotected sample. However, whilst pHRR, THR and TTI are good indicatives of the fire retardant performance of materials, one of the most important factors in evaluating fire retardant behaviour of materials is the MARHE, a parameter directly linked to the heat level given off. It can be considered as a good measurement of the tendency for a fire development in the case of a real situation. According to literature, materials with MARHE values of about $60-75 \mathrm{~kW} / \mathrm{m}^{2}$ would be equivalent to class $B$ materials according to UNE-EN 13501-1, which is the European standard for evaluating reaction 


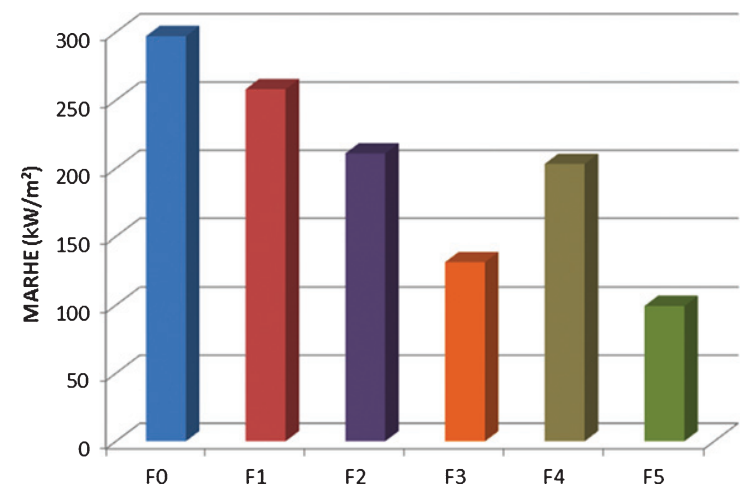

Fig. 3. The effect of FR additive, type and concentration in MARHE values of flax bio-composite laminates.

to fire behaviour of construction products. Figure 3 illustrates the effect of fire retardant fillers on reducing the MARHE value for the protected specimens. All the fire retardant systems investigated display lower MARHE values compared to the unprotected system. Even though flammability of these bio-composites has been successfully reduced through the incorporation of several FR additives, the MARHE values are still above the estimated value needed to achieve Euro Classification $B$. However, current normative for the railway market (UNE 45545, Railway applications - Fire protection on railway vehicles -, 2005) mention a maximum MARHE of $90 \mathrm{~kW} / \mathrm{m}^{2}$ for certain applications which would open up new possibilities for formulation F5.

The combination of APP and ATH (F3 sample) leads to a notable reduction on the MARHE value (55\%) with respect to the unfilled sample, but addition of DPP (F4) to the resin did not show any further improvement but worsens the result compared to F3. Samples containing Exolite 740 performed the best, with MARHE values up to $66 \%$ lower than those corresponding to the reference sample. On the other hand, samples containing only APP performed the worst with MARHE values similar to the unfilled sample.

Finally, resin viscosity is a key parameter from a processing point of view and it was taken into account during the preparation of the different FR formulations. In fibre reinforced polymer composite manufacturing, fibre wetting by the resin is of paramount importance. If the wetting is not good, voids occur at interface between the two that result in polymer composites most susceptible to failure. Fibre wetting is directly related to chemical compatibility between resin and fibres and resin viscosity; thus, lower values will result in easier production and improved quality of the product.

Brookfield viscosity, see Figure 4, increases upon addition of either ATH or APP to the resin. Formulations containing only APP showed a larger increase in viscosity than formulations containing both APP and ATH. It is important to keep in mind that formulations with ATH also contain a low viscosity dispersing agent from BYK which would contribute, not only to improve ATH dispersion within the resin, but also to reduce the viscosity of the mixture. In this work, 175 phr of FR's was the maximum concentration achievable which was considered processable by either resin infusion or pultrusion. Surprisingly, formulation F4, with an additional 12 wt\% DMPP (liquid FR additive, $\eta$ $=250 \mathrm{cps}$ ) did not show any viscosity reduction compared to F3. That result suggests that some unwanted reaction might take place between DMPP and the resin leading to an increase in the viscosity. Formulation containing Exolite $\mathbf{7 4 0}$ has the largest viscosity but at least theoretically it is still possible to pultrude it accordingly to the resin viscosity range established by several authors that goes from 500-3000 cps. 


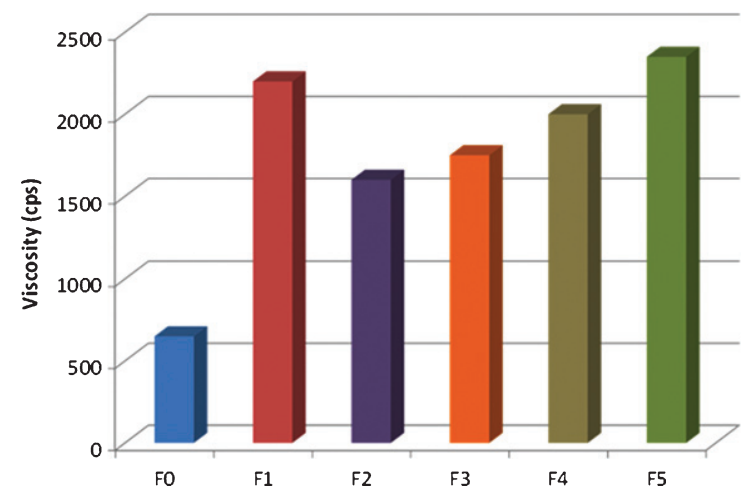

Fig. 4. Brookfield viscosity measurements at $25^{\circ} \mathrm{C}$.

\section{Conclusions}

Aiming at the production of more sustainable low flammability composites, "greener" non-toxic flame retardants additives were added to commercial unsaturated bio-polyester resin and combined with flax fibres. This study has shown that enhancing the fire retardant performance of flax biopolyester composites can be done through the proper combination of FR additives. It was possible to identify several processes that take place in the fire retardant bio-composite laminate during the exposure to a fire/heat source; (i) On one side, water moisture vapour from the decomposition of APP and ATH leads to a reduction of combustible gas concentrations slowing down the burning rate of the laminate, (ii) Incorporation of high amounts of FR additives (50 to 150phr) results in a reduction of the amount of burnable material, and consequently enhanced FR performance, and finally (iii) Thermal decomposition of APP and ATH produces a protective layer at the surface blocking the available oxygen and delaying flame propagation by adiabatic effect.

Main results can be summarized as follows; the use of ATH in combination with APP imparts an improved flame retardant effect on the laminate. A combination of both FR's showed a decrease in the peak heat release rate, total heat release and MARHE values. Reductions of up to $55 \%$ are achieved with loading degrees of $175 \mathrm{phr}$. However, the most promising result was obtained with Exolite 740, the synergistic behaviour among APP and other intumescent additives present in the formula, produces a large additional reduction in the pHRR, THR and MARHE without affecting to its processing performance. On the contrary, a further increase on the concentration of APP/ATH does not justify its use due to the resultant difficulties with increased viscosity, which will result in major processing issues in adopting these materials in fibre reinforced composites.

\section{Acknowledgments}

The research leading to these results has received funding from the European Community's Seventh Framework Programme (FP7) under grant agreement no. 609067 (OSYRIS - forest based composites for façades and interior partitions to improve indoor air quality in new builds and restoration) and grant agreement no. 285689 (BioBuild - High Performance, Economical and Sustainable Biocomposite Building Materials). The authors also thank S. Neira and S. Allue from GAIKER for carrying out the cone calorimeter tests. 


\section{References}

Aziz, S. H., Ansell, M. P., Clarke, S. J., \& Panteny, S. R. (2005). Modified polyester resins for natural fibre composites. Composites Science and Technology, 1(3-4), 525-535.

Babrauskas, V., \& Parker, W. J. (1987). Ignitability measurements with the cone calorimeter. Fire and Materials, 11(1), 31-43.

Babrauskas, V. (1995). Speciman heat fluxes for bench-scale heat release rate testing. Fire and Materials, Proceedings of Interflam, 19(6), 243-252.

Bakhtiyari, S., Taghi-Akbari, L., \& Ashtiani, M. J. (2015). Evaluation of thermal fire hazard of 10 polymeric building materials and proposing a classification method based on cone calorimeter results, Fire and Materials, 39(1), 1-13.

Bismarck, A., Mishra, S., \& Lampke, Th. (2005). Plant fibres as reinforcement for green composites. in 'Natural Fibers, Biopolymers and Biocomposites. Boca Raton: Taylor and Francis, 37-108.

Camino, G., \& Luda, M. (1998). Mechanistic study on intumescence. Fire retardancy of polymers: The use of intumescence. Cambridge: Royal Society of Chemistry.

Dorez, G., Taguet, A., Ferry, L., \& Lopez-Cuesta, J. M. (2013). Thermal and fire behavior of natural fibers/PBS biocomposites. Polymer Degradation and Stability, 98(1), 87-95.

El-Sabbagh A., Steuernagel L., Ziegmann G., Meiners D., \& Toepfer O. (2014). Processing parameters and characterisation of flax fibre reinforced engineering plastic composites with flame retardant fillers. Composites Part B: Engineering, 62, 12-18.

Goutianos, S., Peijs, T., \& Skrifvars, M. (2006). Development of Flax Fibre based Textile Reinforcements for Composite Applications. Applied Composite Materials, 13(4), 199-215.

Hapuarachch, T. D., \& Peijs, T. (2009). Aluminium trihydroxide in combination with ammonium polyphosphate as flame retardants for unsaturated polyester resin. EXPRESS Polymer Letters, 3(11), 743-751.

Hull, T. R., Witkowski, A., \& Hollingbery, L. (2011). Fire retardant action of mineral fillers. Polymer Degradation and Stability, 96(8), 1462-1469.

ISO 5660-1:2002. Reaction-to-fire tests, h. r. (2002). Reaction-to-fire tests, heat release, smoke production and mass loss rate. Part 1: Heat Release Rate (cone calorimeter method). International Standard Organization.

Van de Velde, K., \& Kiekens, P. (2002). Thermal Degradation of Flax: The Determination of Kinetic Parameters with TGA. Journal of Applied Polymer Science, 83(12), 2634-2643.

Kandare, E., Chukwunonso, A. K., \& Kandola, B. K. (2011). The effect of fire-retardant additives and a surface insulative fabric on fire performance and mechanical property retention of polyester composites. Fire and Materials, 35(3), 143-155.

Lazko, J., Landercy, N., Laoutid, F., Dangreau, L., Huguet, M. H., \& Talon O. (2013). Flame retardant treatments of insulating agro-materials from flax short fibres. Polymer Degradation and Stability, 98, 1043-1051.

Levchik, S. V., Levchik, G. F., Camino, G., \& Costa, L. (1995). Mechanism of Action of Phosphorous-Based Flame Retardants in Nylon 6. II. Ammonium Polyphosphate/Talc. Journal of Fire Sciences, 13(1), 43-58.

Ricciardi, M., Antonucci, V., Giordano, M., \& Zarrelli, M. (2012). Thermal decomposition and fire behavior of glass fiber-reinforced polyester resin composites containing phosphate-based fire-retardant additives. Journal of Fire Sciences, 30(4), 318-330.

Matkó, S., Toldy, A., Keszei, S., Anna, P., Bertalan, G., \& Marosi, G. (2005). Flame retardancy of biodegradable polymers and biocomposites. Polymer Degradation and Stability, 88, 138-145.

Schartel, B. (2010). Phosphorus-based Flame Retardancy Mechanisms-Old Hat or a Starting Point for Future Development? Materials, $3(10), 4710-4745$.

Schartel, B., Braun, U., \& Reinemann, S. (2003). Fire retardancy of polypropylene/flax blends. Polymer, 44(20), 6421-6250.

Shen, C. Y., Stahlheber, N. E., \& Dyroff, D. R. (1969). Preparation and characterization of crystalline long-chain ammonium polyphosphates. Journal of the American Chemical Society, 91, 62-67.

Troitzsch J. (2004). Plastics flamability handbook: Principles, regulations, testing and approval. Munich: Hanser Publishers.

(2005). UNE 45545, Railway applications - Fire protection on railway vehicles -.

Wielage, B., Lampke, Th., Marx, G., Nestler, K., \& Starke, D. (1999). Thermogravimetric and differential scanning calorimetric analysis of natural fibres and polypropylene. Thermochimica Acta, 337(1-2), 169-177. 